\title{
Top-down Design of a CS Curriculum for a Computer Games BA
}

\author{
Nuno Fachada \\ HEI-Lab - Digital Human-Environment Interactions Lab \\ Lusófona University \\ Lisboa, Portugal \\ nuno.fachada@ulusofona.pt
}

\begin{abstract}
Computer games are complex products incorporating software, design and art. Consequently, their development is a multidisciplinary effort, requiring professionals from several fields, who should nonetheless be knowledgeable across disciplines.

Due to the variety of skills required, and in order to train these professionals, computer game development (GD) degrees have been appearing in North America and Europe since the late 1990s. Following this trend, several GD degrees have emerged in Portugal. Given the lack of specialized academic staff, not uncommon in younger scientific areas, some of these degrees "borrowed" computer science (CS) programs and faculty within the same institution, leading in some cases to a disconnect between CS theory and practice and the requirements of GD classes.

In this paper, we discuss our experience in adapting the CS curriculum of a three-year computer games BA in accordance with GD requirements. We used a top-down approach, where the game engine used for GD informs the choice of CS topics and programming languages lectured in the CS curriculum. The discussion is centered around the choices taken and the theoretical and empirical rationale behind our decisions.

Preliminary empirical results indicate a substantial increase in GD project quality and a clear improvement in the students' technical skills, as well as in their experimentation and adaptation capabilities.
\end{abstract}

\section{CCS CONCEPTS}

- Applied computing $\rightarrow$ Computer games; Education; $\bullet$ Software and its engineering $\rightarrow$ General programming languages; Design patterns; Object oriented development.

\section{KEYWORDS}

computer games, undergraduate degree, CS curriculum

\section{ACM Reference Format:}

Nuno Fachada and Nélio Códices. 2020. Top-down Design of a CS Curriculum for a Computer Games BA. In Proceedings of the 2020 ACM Conference on Innovation and Technology in Computer Science Education (ITiCSE '20), June 15-19, 2020, Trondheim, Norway. ACM, New York, NY, USA, 7 pages. https://doi.org/10.1145/3341525.3387378

Permission to make digital or hard copies of all or part of this work for personal or classroom use is granted without fee provided that copies are not made or distributed for profit or commercial advantage and that copies bear this notice and the full citation on the first page. Copyrights for components of this work owned by others than the author(s) must be honored. Abstracting with credit is permitted. To copy otherwise, or republish, to post on servers or to redistribute to lists, requires prior specific permission and/or a fee. Request permissions from permissions@acm.org.

ITiCSE '20, June 15-19, 2020, Trondheim, Norway

( 2020 Copyright held by the owner/author(s). Publication rights licensed to ACM. ACM ISBN $978-1-4503-6874-2 / 20 / 06 \ldots \$ 15.00$

https://doi.org/10.1145/3341525.3387378

\author{
Nélio Códices \\ School of Communication, Arts and Information Tech. \\ Lusófona University \\ Lisboa, Portugal \\ nelio.codices@ulusofona.pt
}

\section{INTRODUCTION}

Programming is a fundamental area in computer game development. Arguably, it was the sole skill required for actually making computer games in the past $[44,49]$. However, the emergence of game engines and other development tools has been reducing the relative importance of programming - so much so that today it is possible to develop commercially viable games (even if limited), without writing code $[4,7,13,43]$. Furthermore, computer games have since become complex products incorporating software, design and art. Thus, computer game development has turned into a multidisciplinary effort, requiring professionals from several fields, who should nonetheless be knowledgeable across disciplines [5, 49, 58]. Nevertheless, programming remains an essential competence for creating interesting and original games, and consequently, a crucial component in undergraduate computer game development degrees.

Due to the variety of skills required, and in order to train these professionals, computer game development (GD) degrees have been appearing in North America and Europe since the late 1990s $[21,27,42,59,60]$. Following this trend, several GD degrees have emerged in Portugal [47]. Given the lack of specialized academic staff, not uncommon in younger scientific areas, some of these degrees "borrowed" computer science (CS) programs and faculty within the same institution, leading in some cases to a disconnect between CS theory and practice and the requirements of GD classes. In addition, game programming, as the games themselves, is complex and involves various specializations, such as computer graphics, physics simulation, multithreading, network programming, low-level optimizations, object-oriented programming, artificial intelligence, databases, and so forth [6, 8, 19, 23, 41], So how can computer game programming, with so many particular specializations, be adequately taught in a three to four year undergraduate degree?

First, it is necessary to clearly define the type of degree being offered. Mateas and Whitehead [34] hold that undergraduate courses in computer game development typically fall into one of three categories:

(1) Art oriented, BA

(2) Evenly interdisciplinary, B.Sc. or BA

(3) Technology oriented, B.Sc.

According to the same authors, evenly interdisciplinary programs have solid CS underpinnings. Yet, with respect to CS topics, such programs are more limited in scope than technology-focused degrees. In contrast, interdisciplinary programs put forward a comprehensive combination of game design courses, making them the most challenging to put into practice, according to the same authors. 
The Bachelor in Videogames at Universidade Lusófona de Humanidades e Tecnologias (ULHT) is a three year evenly interdisciplinary BA, open to students coming from various high school areas of study. Consequently, students from areas such as Arts or Humanities are bound to struggle with CS course units. Moreover, the program is enticing for students who enjoy playing computer games - something which is often not reflected in the pleasure of actually creating them.

Having defined the type of computer games program offered by ULHT, the question posed earlier becomes more well-defined: how can CS in general, and programming in particular, be successfully taught in a three-year evenly interdisciplinary BA? In this paper, we discuss, in the context of the above program, our experience in adapting its CS curriculum in accordance with GD requirements. We used a top-down approach where the game engine used for GD informs the choice of CS topics and programming languages lectured in the CS curriculum. The discussion is centered around the choices taken and the theoretical and empirical rationale behind our decisions.

The paper is organized as follows. In Section 2, we review related work concerning CS curriculum design for computer game undergraduate programs. In Section 3, we discuss the implemented CS curriculum and the reasoning behind the choices made. Preliminary results, indicating an increase in GD project quality, are presented in Section 4. An in-depth discussion of these results and a qualitative assessment of the improvements in the students' technical skills takes place in Section 5. Section 6 closes the paper, offering some conclusions.

\section{BACKGROUND}

Most literature concerning the CS component of computer game development is geared towards discussing the inclusion of games and GD in traditional CS degrees, often with the purpose of raising student interest and minimizing dropout $[26,36]$. Here we are essentially interested in games-first accounts, where the CS component serves game design and development needs, and not the opposite. Nonetheless, there are a number of references worth mentioning due to their historic significance.

Jones [27] was one of the first to formally publish his experience in implementing a computer game course, in this case a capstone for an undergraduate CS degree. An industry-driven capstone course on game programming within the context of CS was later presented by Parberry et al. [42]. The focus was on two game programming classes, namely their design philosophy and potential pitfalls. Parberry went into further detail in a subsequent account [41], where various complementary courses, such as math and physics for games, were also discussed. Ficocelli and Gregg [21] proposed a four-year B.Sc. degree on computer game development with the dual goal of satisfying the needs of the game industry and not compromising the integrity of the computing component of a "normal" CS bachelor degree - thus their proposal was heavily inclined towards CS. In reference [10], Coleman et al. discuss their initiatives for developing a game design and programming concentration in an undergraduate CS program, presenting an example course sequence. Zyda [59] presented a cross-disciplinary double major B.Sc. in CS and GD degree, with CS as its core, claiming the program should in fact be harder than a regular CS degree. Mateas and Whitehead [34] described the most significant design issues concerning the development of game-oriented undergraduate degree programs, including issues concerning the degree's CS content. Peng [43] presented an introductory course for video game development, used for initiatives in developing a gaming minor in an undergraduate CS curriculum.

More relevant to the present work are references which go into additional detail of how particular CS course contents influence GD methodologies, and vice versa. For example, Argent et al. [3] discussed the process of building a flexible GD undergraduate program, in which students can specialize in different aspects of game development, depending on whether they chose the B.Sc. or BA degree options, the former having CS as its fundamental core. In particular, the authors discussed the adaptation of classical CS classes for students interested in GD, reporting that the use of ActionScript for basic programming, followed by $\mathrm{C}++$, simplified the introduction of the latter, given the syntax similarities between the languages. In reference [60], Zyda et al. shared details on the operation of a CS game degree program, asserting that, although the program is $\mathrm{C}++$-oriented due to industry feedback, courses featuring Java, $\mathrm{C \#}$ and game-specific hardware programming were also lectured. Kessler et al. [29] discussed a program which brings together CS and Film Studies degrees in an effort to teach both computer game development and computer animation, offering ActionScript, $\mathrm{C}++$ and $\mathrm{C \#}$ lectures over a number of courses. A common thread in these works is the use of $\mathrm{C}++$, a proposition further analyzed in Subsection 3.2.

Finally, a note on the International Game Developer's Association (IGDA) curriculum framework [1] and on the ACM/IEEE CS curriculum guidelines for undergraduate programs [51]. The former presents a conceptual guide for game-related educational programs, including a "Game Programming" core topic with various sub-topics. While it presents an interesting overview, it does not go into great detail on what specific CS aspects to give preference to or how to organize the topics themselves [24]. The latter is aimed at general CS curricula, without a specific computer games section. Nonetheless, several topics related to game development are mentioned [35]. Although both frameworks are relevant for developing high-level curriculum outlines, implementation details will strongly depend on context, as will be shown in following sections.

\section{METHODS}

In this work, and in order to answer the question posed in Section 1, we believe CS classes should aim for two goals:

(1) A more general goal, which is to provide students with the foundations that enable them to absorb general programming, math and physics concepts, developing their logical and algorithmic thinking [22].

(2) A specific goal, which consists in learning the tools and concrete concepts that enable students to work fluidly in the game engine of choice, as specified by GD requirements [15].

The second goal frames CS topics in a top-down logic, as degreespecific GD requirements guide how these topics are prepared. GD 
requirements, presented in Subsection 3.1, include not only the game engine of choice, but also advanced CS topics considered essential for the type of games to be developed. In Subsections 3.2-3.4, we discuss the CS curriculum, designed based on GD requirements, particularly with regard to the choice of programming languages to teach, as well as the selection of support topics. The practical implementation of the curriculum, based on all the previous choices, is presented in Subsection 3.5. With the purpose of contextualizing the results and discussion, the former curriculum is briefly discussed in Subsection 3.6.

\subsection{GD requirements}

A game engine should simplify and speed up the development process, allowing students to create interesting games in a short amount of time time, e.g., in a few months. The task of finding the most appropriate game engine for a given degree is not trivial, and there are several reports of difficulties in this choice $[15,16$, 42,43 ]. Dickson [15] suggests using the Unity game engine [54] to teach game development. Considering that Unity is widely used in the industry [52], and is even used for teaching GD at secondary schools [11], it is a natural choice as the game engine of choice for ULHT's Bachelor in Videogames. However, note that Unity is a GD requirement we are not defending nor criticizing. We simply use it to inform CS curriculum design.

There are several advanced CS topics directly applicable to the development of computer games. However, there is not enough room for many of these in a three-year evenly interdisciplinary BA, as is the case discussed here. As such, and for the games intended to be developed by students at ULHT, Artificial Intelligence (AI) $[38,57]$ is deemed essential. While there are many valid reasons for such a choice [45], an important consideration in this case is the ongoing collaboration with the HEI-Lab research group ${ }^{1}$, which works on and/or makes use of AI subject matters such as player modeling, AI game design and procedural content generation [33].

\subsection{The C\# language and its implications on lectured materials}

3.2.1 The C\# programming language. The main programming language used in ULHT's Bachelor in Videogames degree is C\#, since it is the scripting language used by Unity. It is a medium-level (with respect to hardware), object-oriented programming language with automatic memory management. The language supports functional and event-oriented programming paradigms, as well as manual memory management in specific cases. In short, it is a versatile language [2]. Moreover, $\mathrm{C} \#$ is used as a scripting language in a number of game engines besides Unity, such as Godot [32], CryEngine [12], Xenko [46], MonoGame [56] or Unigine [53]. Its syntax is nearly identical to Java and very similar to $\mathrm{C}$ and $\mathrm{C}++$. Thus, we believe the focus on C\# will not limit students going forward - on the contrary: it offers a strong base for future knowledge acquisition within game development.

A possible limitation in this choice concerns the fact that $\mathrm{C}++$ has been the de facto standard in the game industry for many years $[24,26] . \mathrm{C}++$ is also the language used for developing games in the Unreal Engine [18], itself an industry standard [52]. Nonetheless,

\footnotetext{
${ }^{1}$ http://hei-lab.ulusofona.pt/
}

there are also good reasons to avoid $\mathrm{C}++$ in a three-year evenly interdisciplinary BA. $\mathrm{C}++$ is a large and complex language, with multiple versions and various, often version-dependent ways of achieving common tasks [38]. It is a difficult language to master in a three-year degree, especially a BA. There is, inclusively, a rather negative report concerning the use of $\mathrm{C}++$ and Unreal Engine for teaching purposes, which concludes that the engines' blueprints visual scripting system is the only feasible choice for game creation in a short amount of time [16]. The problem becomes less relevant if we consider that: a) the $\mathrm{C} \#$ inheritance syntax is based on its $\mathrm{C}++$ counterpart; b) $\mathrm{C}++$ is itself built upon the $\mathrm{C}$ programming language, which is itself taught in our degree, as discussed in Subsection 3.3. In conclusion, we believe that the choice of $\mathrm{C \#}$ as the degree's programming language adequately prepares students for a possible, post-degree transition to $\mathrm{C}++$, while not undermining more art and design-oriented students.

3.2.2 Implications on lectured materials. The choice of C\# has important implications for the topics lectured in CS courses. Object orientation is itself a programming paradigm that students have to learn to reason about. It is generally difficult to determine the level of abstraction to use, in particular the number of classes and the relations between them. Together with automatic memory management, object orientation draws the programmer away from the hardware. It is perfectly possible for someone to have a good knowledge of the C\# language, namely its syntax and API, and simultaneously be unable to produce efficient and architecturally sound designs - fundamental characteristics in the development of computer games [40].

Thus, it becomes crucial that the teaching of object-oriented programming is taken to a broader and more detailed level in the curriculum. In particular, it is our opinion that fundamental principles of object-oriented programming (e.g., SOLID), as well as design patterns, be taught. Regarding the latter, the focus should be on design patterns for games, which take into account important lowlevel optimizations $[8,24,40,50]$. Of course, it is also important to include UML class diagrams in the curriculum, as these are a practical way to visually communicate class designs $[8,31,50]$.

The choice of $\mathrm{C \#}$ as the main language to teach in the course also presents an important advantage with broader implications for the selection of advanced topics. In particular, the C\# language offers LINQ - language integrated queries - which allow to natively perform SQL-style queries on data structures and databases from within code. Consequently, the allocation of a few hours of classes to learn LINQ partially minimizes potential negative impacts caused by not offering a dedicated Databases class.

\subsection{Languages for learning how to program}

Although simpler than $\mathrm{C}++$, the $\mathrm{C}$ \# programming language draws in a number of features and programming paradigms which make it less appropriate to learn programming from scratch [20]. As such, and with the added benefit of expanding the horizons of students, we believe other types of simpler programming languages should be lectured initially. We propose two diametrically opposed languages, offered in two distinct courses during the first semester, namely: a) a low-level, close to the hardware language; b) a highlevel scripting language. The former should be offered in the context 
of (and side by side with) basic computer architecture concepts, while the latter should be explored with the goals of developing algorithmic thinking and fast prototyping. The objective is that students understand the fundamentals when they start using an intermediate-level language, such as C\#. In other words, the goal is for students to understand the cost of abstractions and for them to be able to identify and eliminate performance problems.

We have chosen $\mathrm{C}$ as the low-level programming language to teach programming in the degree's first semester. On the other hand, we have chosen Python as the language to teach high-level programming and prototyping. The reasons for these choices are detailed in the following paragraphs.

3.3.1 C as the low-level language. The $\mathrm{C}$ programming language is simple, expressive and effective, and it is supported in virtually every type of platform [28, 39]. It is the lingua franca of systems programming $[28,48]$, and its syntax serves as the basis for many other languages, such as $\mathrm{C}++, \mathrm{C} \#$ and Java. In the case of $\mathrm{C}++$, this relationship is even stronger, as $\mathrm{C}$ is essentially a subset of $\mathrm{C}++$. The fact of it being very close to hardware helps in understanding how a computer works, thus enabling students to learn and apply performance optimizations, a skill in high demand within the game industry [24]. Finally, and in spite of C being a widely used language for the teaching of programming in general, the existence of computer game-oriented libraries, such as Allegro ${ }^{2}$, $\mathrm{RayLib}^{3}$ or $\mathrm{SDL}^{4}$, further promotes $\mathrm{C}$ within the specific case of computer game programming.

3.3.2 Python as the high-level language. Considered as an excellent language for introductory programming [9], Python presents a simple syntax, with blocks defined by code indentation, in contrast with $\mathrm{C}$ or $\mathrm{C \#}$. We believe that this feature forces students to understand the importance of indentation, besides broadening their horizons in regard to different types of syntax. The quantity and quality of libraries available for Python is extraordinary, allowing the fast prototyping of all kinds of software, naturally including computer games. Furthermore, Python is used as a scripting language in several engines (e.g., Blender, Cocos2d, Irrlicht, Maya or Panda3D), as well as in a few games (e.g., Battle for Wesnoth, Civilization IV, CodeSubWars or Minecraft).

\subsection{Maths and physics for games}

Maths and physics are fundamental components in computer game development: practically every game involves mathematical models and/or physics simulations [10]. In particular:

- Computer Graphics theory is based in linear algebra concepts $[17,27]$

- The use of a game engine does not exempt the user of knowing these disciplines, on the contrary: a good knowledge of Maths and Physics is essential to understand and correctly use the scripting APIs of game engines [27, 43].

- The game industry itself requires professionals with solid knowledge in Maths and Physics [42].

\footnotetext{
$\overline{{ }^{2} \text { https://liballeg.org/ }}$

${ }^{3}$ https://www.raylib.com/

${ }^{4}$ https://www.libsdl.org/
}

There are several descriptions of these subjects available in a range of books and articles, among which we highlight the accessible and informal approach proposed by Dunn and Parberry [17], as well as the complete and detailed methodology presented by Lengyel [30].

In the program being discussed, we have two course units exclusively dedicated to Maths and Physics for games, with their program based in the book of Dunn and Parberry [17]. In the first course unit [14], the exercises, examples and projects are implemented in Python (this language being simultaneously lectured in a programming course unit), with the PyGame [37], NumPy [55] and Matplotlib [25] libraries. In the second course unit, Python is still used, but at some point C\# and Unity are introduced, in order for students to be able to put the learned subjects in context, within the scope of the game engine used in the degree.

\subsection{Practical implementation}

Figure 1 shows the CS program contents discussed in the previous sections at the level of the course units, within the context of the degree's first four semesters. The first semester has a strong CS component, with three dedicated course units. Students learn how to program using $\mathrm{C}$ and Python, following the reasoning presented in Subsection 3.3, with the Maths and Physics for Games unit being taught simultaneously, using the Python language for prototyping. Maths and Physics for Games continues to be offered throughout the second semester, but with more advanced concepts. At the same time, object-oriented programming in C\# is introduced - this language is also starting to be used in Unity, in a GD course unit. In the third semester (second year), the CS course unit weight decreases considerably, with only a single exclusively dedicated class. This course unit deals with advanced concepts in objectoriented programming, such as design patterns. The objective is that, by the end of this semester, students are proficient not only in C\#, but also in structured and computationally efficient class design. Finally, in the fourth semester, an AI for games class is offered, being the last course unit with exclusive CS contents in the degree.

\subsection{A note on the previous curriculum}

The previous curriculum was structurally similar to the top-down approach presented here. The main differences lie within the syllabuses of the CS course units, which were not clearly targeted at GD students. More specifically, the math programs where dedicated to classical calculus, with no programming involved [14]. In turn, the programming course units were designed around $C$ and Java, but again, not particularly geared towards computer game development. We believe, as stated in the Introduction, this was a direct consequence of GD being a relatively recent scientific area, with the institution making use of existing CS programs and faculty when originally envisioning the degree.

\section{PRELIMINARY RESULTS}

The curriculum described in this paper began its deployment in $2017 / 18$, initially targeting the first year, and moving forward since then. The presented results span the 2016/17-2018/19 time period, and focus on the Game Development II (GD2, 3rd semester) and Game Development III (GD3, 4th semester) course units. There are 


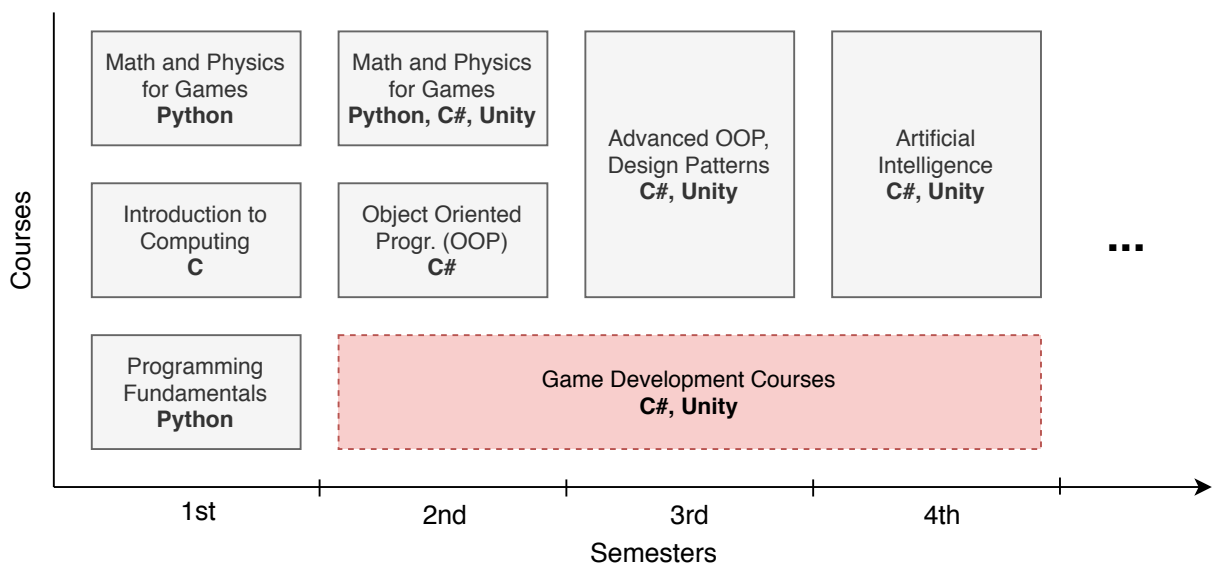

Figure 1: Practical implementation of the CS curriculum for ULHT's Bachelor in Videogames. Solid grey boxes correspond to CS courses, with syllabus contents. Dashed light red box encompasses several game development courses over the semesters.

\begin{tabular}{rrrrrrrr}
\hline & \multicolumn{3}{c}{ GD2 } & & \multicolumn{3}{c}{ GD3 } \\
\cline { 2 - 5 } \cline { 6 - 8 } & $2016 / 17$ & $2017 / 18$ & $2018 / 19$ & & $2016 / 17$ & $2017 / 18$ & $2018 / 19$ \\
\hline$n$ & 21 & 28 & 30 & 20 & 21 & 32 \\
$\bar{x}$ & 10.05 & 11.64 & 13.67 & & 11.35 & 11.29 & 12.63 \\
$\widetilde{x}$ & 11.00 & 12.00 & 15.50 & & 12.00 & 10.00 & 15.00 \\
\hline
\end{tabular}

Table 1: Summary statistics for GD2 and GD3 course units for academic years 2016/17-2018/19. Number of students enrolled, $n$, mean grade, $\bar{x}$, and median grade, $\widetilde{x}$.

two reasons for this choice. First, the quality of the games created in second year GD course units, reflected in the respective grades, can be used to assess the impact of the curriculum after a full year of its implementation. Second, the teacher and evaluation criteria of the GD course units were the same during this period, allowing for a fair comparison.

Second year students in 2018/19 were the first to enroll in GD2 and GD3 under the new curriculum. Thus, their grades, given in a 0-20 scale, can be compared with grades given in the two previous academic years. Table 1 shows the mean and median of GD2 and GD3 grades during this time period, while Figure 2 shows the respective grade distributions. As can be observed, average grades for both courses improved under the new curriculum (2018/19). Likewise, grade distribution is centered around higher values.

\section{DISCUSSION}

Going further in the preliminary results, we highlight (i) the increase in the number of high-quality projects (grade above 16), and (ii) the increase in the average quality of the projects. Before the implementation of the new curriculum, the number of highquality projects was limited to 1-3 per semester. In the academic year 2018/19, the number of high-quality projects increased considerably: six projects in GD2 and four projects in GD3. We also observed a decrease in the number of low-quality projects (grade below 13). In previous years, as much as half of the projects were included in this category. However, during 2018/19 the situation was entirely different. Only two projects in GD2 and three in GD3 were considered low-quality. This means that there was an increase in the average quality of the projects under the new curriculum: in GD2, we observed ten projects of average and high quality (grade equal to or above 13), and in GD3 we observed eight.

Nonetheless, and while these preliminary grade-based results allow us to perform an objetive assessment, there are a number of somewhat subjective insights that can also be discussed. Perhaps the most important result we were able to obtain was the substantial improvement in the students' programming knowledge. Not only did this lead to the measurable results already described, but also to two extremely important outcomes. First, students were clearly able to implement their initial visions for the projects, in a more or less comprehensive way. Usually, students would idealize concepts that would later be forced to limit or substantially modify due to their lack of technical knowledge. During 2018/19, every project generally accomplished the course units' objectives, as well as the self-proposed goals, with the exception of the low-quality projects. It is important to note that this was also achieved by students who, according to themselves, had "considerably limited programming knowledge". Second, it was obvious that many groups were more demanding with themselves, by trying to explore ideas and concepts beyond those required in the course unit and that required research, including students who were not completely comfortable with programming. This evidences a level of technical skill above what was observed in the previous academic years.

Following the previous paragraph, it is important to note that the students' higher technical skills also enabled them to react to the teachers' feedback in a much more effective fashion. Where in previous years students found it very hard to move away from their projects' initial code, in the academic year being analyzed they were able to effectively test and validate their own ideas, as well as those of their colleagues or teachers, without jeopardizing the stability of the projects. The code they developed was much more flexible, modular, parameterized and organized to work in team and maximize experimentation. 


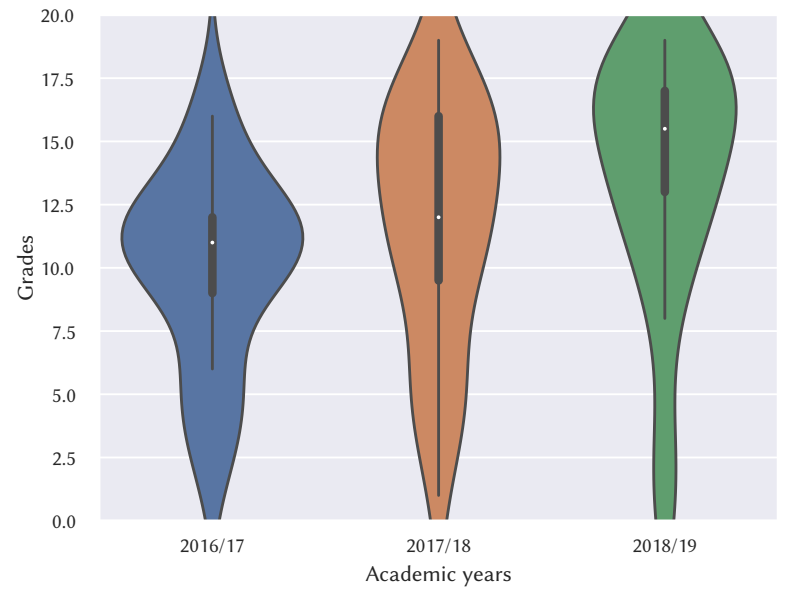

(a) GD2.

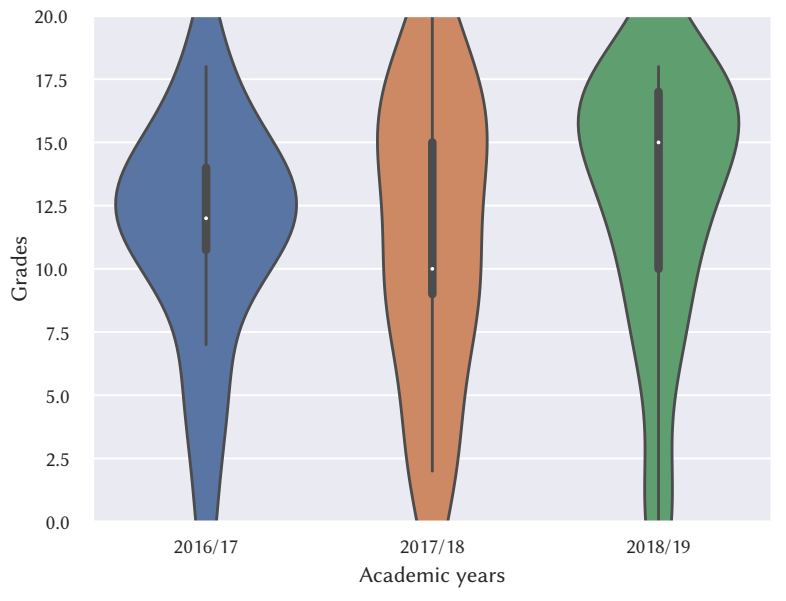

(b) GD3.

Figure 2: Violin plots showing the distribution of grades in GD course units across academic years.

Finally, we would like to note that, before the introduction of the new curriculum, the main cause for failure or low-quality of the projects was almost always the students' lack of technical skills or programming-oriented logical reasoning. There was a very big gap between the projects' conceptualization and its translation into a code that would transform them in tangible products. In the 2018/19 academic year, this gap was considerably reduced, and the causes for projects not reaching their full potential were more diverse: lack of attendance, problems in organizing the groups, some extent of lack of imagination/culture in computer games, and difficulties in conciliating the required work for the different course units.

For all of the reasons above, it is possible to conclude that the proposed top-down curriculum implementation has resulted in a substantial improvement in the students' work and their projects' potential, as these showcase the current quality of the program and the competences of the students as they prepare to enter a demanding industry.

\section{CONCLUSIONS}

In this work, we discussed our experience in using a top-down approach to adapt the CS curriculum of a three-year computer games BA in accordance with GD requirements, answering the question of how can computer game programming be adequately lectured in a such a degree. The first part of this answer consisted in defining the intended goals, namely, to promote the logical and algorithmic reasoning of the students, as well as to provide them with ways of working proficiently in the course's chosen game engine. From here, we defined a top-down approach, where the choice of the game engine informs the CS topics and programming languages lectured in the CS curriculum. Preliminary results show that the quality of the games created in the GD course units, as well as the students' technical development, have substantially improved, thus validating the proposed strategy.

\section{ACKNOWLEDGMENTS}

The authors would like to thank André Fachada for proof-reading the text. The authors would also like to thank the anonymous referees for their valuable comments and helpful suggestions. This work is supported by Fundação para a Ciência e Tecnologia under Grant No.: UIDB/05380/2020 (HEI-Lab).

\section{REFERENCES}

[1] 2008. IGDA Curriculum Framework.

[2] Joseph Albahari and Ben Albahari. 2017. C\# 7.0 in a Nutshell: The Definitive Reference (first ed.). O’Reilly Media.

[3] Lawrence Argent, Bill Depper, Rafael Fajardo, Sarah Gjertson, Scott T. Leutenegger, Mario A. Lopez, and Jeff Rutenbeck. 2006. Building a game development program. Computer 39, 6 (June 2006), 52-60. https://doi.org/10.1109/MC.2006.189

[4] Jason Astle-Adams. 2018. How To Make Games Without Programming. GameDev.Net (Oct. 2018). https://www.gamedev.net/articles/ programming/general-and-gameplay-programming/how-to-make-gameswithout-programming-r4987/ Last accessed on 14/08/2019.

[5] Bob Bates. 2004. Game Design. Premier Press.

[6] Brendan Burns. 2008. Teaching the Computer Science of Computer Games. Journal of Computing Sciences in Colleges 23, 3 (Jan. 2008), 154-161. http://dl. acm.org/citation.cfm?id=1295109.1295144

[7] Christian Cawley. 2015. How to Make Video Games Without Any Programming. MakeUseOf (Aug. 2015). https://www.makeuseof.com/tag/make-video-gameswithout-programming/ Last accessed on 19/07/2019.

[8] Kajal Claypool and Mark Claypool. 2005. Teaching Software Engineering Through Game Design. In Proceedings of the 10th Annual SIGCSE Conference on Innovation and Technology in Computer Science Education (Caparica, Portugal) (ITiCSE '05). ACM, New York, NY, USA, 123-127. https://doi.org/10.1145/1067445. 1067482

[9] Alan Cleary, Lucas Vandenbergh, and John Peterson. 2015. Reactive Game Engine Programming for STEM Outreach. In Proceedings of the 46th ACM Technical Symposium on Computer Science Education (Kansas City, Missouri, USA) (SIGCSE '15). ACM, New York, NY, USA, 628-632. https://doi.org/10.1145/2676723.2677312

[10] Ron Coleman, Mary Krembs, Alan Labouseur, and Jim Weir. 2005. Game Design \& Programming Concentration Within the Computer Science Curriculum. In Proceedings of the 36th SIGCSE Technical Symposium on Computer Science Education (St. Louis, Missouri, USA) (SIGCSE '05). ACM, New York, NY, USA, 545-550. https://doi.org/10.1145/1047344.1047514

[11] Oswald Comber, Renate Motschnig, Hubert Mayer, and David Haselberger. 2019. Engaging Students in Computer Science Education through Game Development with Unity. In 2019 IEEE Global Engineering Education Conference (EDUCON). IEEE, 199-205. https://doi.org/10.1109/EDUCON.2019.8725135 
[12] Crytek. 2019. CryEngine. https://www.cryengine.com/

[13] Nikunj Dalal, Parth Dalal, Subhash Kak, Pavlo Antonenko, and Susan Stansberry 2009. Rapid digital game creation for broadening participation in computing and fostering crucial thinking skills. International fournal of Social and Humanistic Computing 1, 2 (2009), 123-137. https://doi.org/10.1504/IJSHC.2009.031002

[14] Diogo de Andrade and Nuno Fachada. 2020. Fun maths for all game development students. In Proceedings of the 2020 ACM Conference on Innovation and Technology in Computer Science Education (Trondheim, Norway) (ITiCSE '20). ACM, New York, NY, USA. https://doi.org/10.1145/3341525.3393992

[15] Paul E. Dickson. 2015. Using Unity to Teach Game Development: When You'Ve Never Written a Game. In Proceedings of the 2015 ACM Conference on Innovation and Technology in Computer Science Education (Vilnius, Lithuania) (ITiCSE '15). ACM, New York, NY, USA, 75-80. https://doi.org/10.1145/2729094.2742591

[16] Paul E. Dickson, Jeremy E. Block, Gina N. Echevarria, and Kristina C. Keenan 2017. An Experience-based Comparison of Unity and Unreal for a Stand-alone 3D Game Development Course. In Proceedings of the 2017 ACM Conference on Innovation and Technology in Computer Science Education (Bologna, Italy) (ITiCSE '17). ACM, New York, NY, USA, 70-75. https://doi.org/10.1145/3059009.3059013

[17] Fletcher Dunn and Ian Parberry. 2011. 3D Math Primer for Graphics and Game Development (second ed.). CRC Press.

[18] Epic Games. 2019. Unreal Engine. https://www.unrealengine.com/

[19] Nuno Fachada. 2018. Teaching database concepts to video game design and development students. Revista Lusófona de Educação 40, 40 (2018), 151-165. https://doi.org/10.24140/issn.1645-7250.rle40.10

[20] Muhammad Shoaib Farooq, Sher Afzal Khan, Farooq Ahmad, Saeed Islam, and Adnan Abid. 2014. An Evaluation Framework and Comparative Analysis of the Widely Used First Programming Languages. PLOS ONE 9, 2 (Feb. 2014), 1-25. https://doi.org/10.1371/journal.pone.0088941

[21] Libero Ficocelli and David Gregg. 2005. B.Sc. Computer Game development... Why not?. In Proceedings of DiGRA 2005 Conference: Changing Views - Worlds in Play. DiGRA: Digital Games Research Association.

[22] Gerald Futschek. 2006. Algorithmic Thinking: The Key for Understanding Computer Science. Lecture Notes in Computer Science, Vol. 4226. Springer Berlin Heidelberg, 159-168. https://doi.org/10.1007/11915355_15

[23] Nicole Herbert, Kristy de Salas, Ian Lewis, Julian Dermoudy, and Leonie Ellis. 2014 ICT Curriculum and Course Structure: The Great Balancing Act. In Proceedings of the Sixteenth Australasian Computing Education Conference (Auckland, New Zealand) (ACE '14), Vol. 148. Australian Computer Society, Inc., Darlinghurst, Australia, Australia, 21-30. http://dl.acm.org/citation.cfm?id=2667490.2667493

[24] Michael Hewner and Mark Guzdial. 2010. What Game Developers Look for in New Graduate: Interviews and Surveys at One Game Company. In Proceedings of the 41st ACM Technical Symposium on Computer Science Education (Milwaukee, Wisconsin, USA) (SIGCSE '10). ACM, New York, NY, USA, 275-279. https: //doi.org/10.1145/1734263.1734359

[25] John D. Hunter. 2007. Matplotlib: A 2D graphics environment. Computing in Science \& Engineering 9, 3 (2007), 90-95. https://doi.org/10.1109/MCSE.2007.55

[26] Barry Ip. 2012. Fitting the Needs of an Industry: An Examination of Games Design, Development, and Art Courses in the UK. ACM Transactions on Computing Education 12, 2, Article 6 (April 2012), 35 pages. https://doi.org/10.1145/2160547. 2160549

[27] Randolph M. Jones. 2000. Design and Implementation of Computer Games: A Capstone Course for Undergraduate Computer Science Education. In Proceedings of the Thirty-first SIGCSE Technical Symposium on Computer Science Education (Austin, Texas, USA) (SIGCSE '00). ACM, New York, NY, USA, 260-264. https: //doi.org/10.1145/330908.331866

[28] Damien Katz. 2013. The Unreasonable Effectiveness of C. Personal Blog. http:// damienkatz.net/2013/01/the_unreasonable_effectiveness_of_c.html Last accessed on $01 / 08 / 2019$.

[29] Robert Kessler, Mark van Langeveld, and Roger Altizer. 2009. Entertainment Arts and Engineering(or How to Fast Track a New Interdisciplinary Program). In Proceedings of the 40th ACM Technical Symposium on Computer Science Education (Chattanooga, TN, USA) (SIGCSE '09). ACM, New York, NY, USA, 539-543. https //doi.org/10.1145/1508865.1509049

[30] Eric Lengyel. 2012. Mathematics for 3D game programming and computer graphics (third ed.). Cengage Learning.

[31] Scott Leutenegger and Jeffrey Edgington. 2007. A Games First Approach to Teaching Introductory Programming. In Proceedings of the 38th SIGCSE Technical Symposium on Computer Science Education (Covington, Kentucky, USA) (SIGCSE '07). ACM, New York, NY, USA, 115-118. https://doi.org/10.1145/1227310.1227352

[32] Juan Linietsky and Ariel Manzur. 2019. Godot Engine. https://godotengine.org/

[33] Filipe Luz, Nuno Fachada, and Roberto Junior. 2018. Biofeedback Game Design. In Play2Learn 2020 (Lisbon, Portugal). 350

[34] Michael Mateas and Jim Whitehead. 2007. Design issues for undergraduate game-oriented degrees. In Proceedings of the 2007 Microsoft Academic Days on Game Development in Computer Science Education. 85-89.

[35] Monica M. McGill. 2009. Defining the Expectation Gap: A Comparison of Industry Needs and Existing Game Development Curriculum. In Proceedings of the 4th International Conference on Foundations of Digital Games (Orlando, Florida) (FDG
'09). ACM, New York, NY, USA, 129-136. https://doi.org/10.1145/1536513.1536542

[36] Monica M. McGill. 2012. The Curriculum Planning Process for Undergraduate Game Degree Programs in the United Kingdom and United States. ACM Transactions on Computing Education (TOCE) 12, 2, Article 7 (April 2012), 47 pages. https://doi.org/10.1145/2160547.2160550

[37] Will McGugan. 2007. Beginning game development with Python and Pygame: from novice to professional. Apress.

[38] Ian Millington. 2019. AI for Games (third ed.). CRC Press, Boca Raton, FL, USA. https://doi.org/10.1201/9781351053303

[39] Edaqa Mortoray. 2012. What's to love about C? Musing Mortoray. https: //mortoray.com/2012/06/11/whats-to-love-about-c/ Last accessed on 12/08/2019.

[40] Robert Nystrom. 2014. Game programming patterns. Genever Benning. https: //gameprogrammingpatterns.com/

[41] Ian Parberry. 2011. Challenges and opportunities in the design of game programming classes for a traditional computer science curriculum. Fournal of Game Design and Development Education 1 (2011), 4-17. Issue 1.

[42] Ian Parberry, Timothy Roden, and Max B. Kazemzadeh. 2005. Experience with an Industry-driven Capstone Course on Game Programming: Extended Abstract. In Proceedings of the 36th SIGCSE Technical Symposium on Computer Science Education (St. Louis, Missouri, USA) (SIGCSE '05). ACM, New York, NY, USA, 91-95. https://doi.org/10.1145/1047344.1047387

[43] Chao Peng. 2015. Introductory game development course: A mix of programming and art. In 2015 International Conference on Computational Science and Computational Intelligence (CSCI). IEEE, 271-276. https://doi.org/10.1109/CSCI.2015.152

[44] Jeremy Reimer. 2005. Cross-platform game development and the next generation of consoles. Ars Technica (Aug. 2005). https://arstechnica.com/features/2005/11/ crossplatform/ Last accessed on 14/08/2019.

[45] Timothy E. Roden and Rob LeGrand. 2013. Growing a computer science program with a focus on game development. In Proceeding of the 44th ACM technical symposium on Computer science education. ACM, 555-560.

[46] Silicon Studio. 2019. Xenko. https://xenko.com/

[47] Sociedade Portuguesa de Ciências dos Videojogos. 2019. Ensino de Videojogos. http://www.spcvideojogos.org/ensino Last accessed on 14/08/2019.

[48] Joel Spolsky. 2005. Advice for Computer Science College Students. Joel on Software. https://www.joelonsoftware.com/2005/01/02/advice-for-computerscience-college-students/ Last accessed on 15/09/2019.

[49] Nathan R. Sturtevant, H. James Hoover, Jonathan Schaeffer, Sean Gouglas, Michael H. Bowling, Finnegan Southey, Matthew Bouchard, and Ghassan Zabaneh. 2008. Multidisciplinary Students and Instructors: A Second-year Games Course. In Proceedings of the 39th SIGCSE Technical Symposium on Computer Science Education (Portland, OR, USA) (SIGCSE '08). ACM, New York, NY, USA, 383-387. https://doi.org/10.1145/1352135.1352269

[50] Elizabeth Sweedyk and Robert M. Keller. 2005. Fun and Games: A New Software Engineering Course. In Proceedings of the 10th Annual SIGCSE Conference on Innovation and Technology in Computer Science Education (Caparica, Portugal) (ITiCSE '05). ACM, New York, NY, USA, 138-142. https://doi.org/10.1145/1067445. 1067485

[51] The Joint Task Force on Computing Curricula. 2013. Computer Science Curricula 2013. ACM and the IEEE Computer Society. https://doi.org/10.1145/2534860

[52] Marcus Toftedahl and Henrik Engström. 2019. A Taxonomy of Game Engines and the Tools that Drive the Industry. In DiGRA '19 - Proceedings of the 2019 DiGRA International Conference: Game, Play and the Emerging Ludo-Mix, Akinori Nakamura (Ed.). DiGRA: Digital Games Research Association.

[53] Unigine Corp. 2019. Unigine. https://unigine.com/

[54] Unity Technologies. 2018. Unity®. https://unity3d.com/

[55] Stéfan van der Walt, S. Chris Colbert, and Gaël Varoquaux. 2011. The NumPy Array: A Structure for Efficient Numerical Computation. Computing in Science \& Engineering 13, 2 (2011), 22-30. https://doi.org/10.1109/MCSE.2011.37

[56] Steve Williams and Tom Spilman. 2019. MonoGame. http://www.monogame.net/

[57] Georgios N. Yannakakis and Julian Togelius. 2018. Artificial Intelligence and Games. Springer. http://gameaibook.org.

[58] Bernard Yee, David Sturman, and Steven Feiner. 2007. Integrating Video Game Development Experience in an Academic Framework. In Proceedings of the 2007 Microsoft Academic Days on Game Development in Computer Science Education. 28-32.

[59] Michael Zyda. 2006. Educating the next generation of game developers. Computer 39, 6 (June 2006), 30-34. https://doi.org/10.1109/MC.2006.197

[60] Michael Zyda, Victor Lacour, and Chris Swain. 2008. Operating a Computer Science Game Degree Program. In Proceedings of the 3rd International Conference on Game Development in Computer Science Education (Miami, Florida) (GDCSE '08). ACM, New York, NY, USA, 71-75. https://doi.org/10.1145/1463673.1463688 